\title{
TWO-SIDED MARKET AS TECHNOLOGICAL TEMPLATE FOR EXHIBITION BUSINESS MODEL
}

\author{
Kirill Simonov \\ Faculty of Economics, Lomonosov Moscow State University, 1-46 Leninskie Gory, 119991, Moscow, Russia \\ E-mail: kirill.simonov.msu@yandex.ru
}

Received 11 March 2020; accepted 04 May 2020

\begin{abstract}
Purpose of the study - to form two-sided network market on discrete sequence of thematically identical short-term periodic trade shows. Methods of the investigation are based on the theory of twosided markets, the theory of industry markets and entrepreneurship, management theory, logistics theory, the theory of systems. Results of the investigation: process model was developed for transforming platform's resources and its parties into intermediary services of exhibition organizer; exhibition market was proved to belong to the category of Rochet \& Tirole markets; toolkit of two-sided markets theory was used to develop the concept of value creation management in exhibition market network; features of logistics support for exhibition business were analyzed. All these findings lay foundations of exhibition two-sided network markets theory, created to provide methodological support for exhibition business.
\end{abstract}

Keywords: trade show, platform, network effects, logistics system.

JEL Classification: D47, M21, L10.

\section{Introduction}

Annualy approximately 32 thousand significant trade shows in $\mathrm{B} 2 \mathrm{~B}$ or $\mathrm{B} 2 \mathrm{C}+\mathrm{B} 2 \mathrm{C}$ format are held all over the world. Their total net area is 125 million sqm, the number of visitors is 303 million, the number of exhibitors is 5 million. These events feature exhibitors from 180 countries (UFI, 2020). Global exhibition sector is based on a total of 35 million sqm of capacity (UFI, 2017).

Trade shows are effective events to promote innovations, as well as sensitive indicators of the economy and catalysts for its development. Global trade shows directly generate more output (business sales) than many large global sectors. In 2019, trade shows contributed (directly and indirectly) to the conclusion of trade deals worth 275 billion euros and provided the creation of 3.2 million jobs. Trade shows' contribution to global GDP was 167 billion euros (UFI, 2019).

Trade shows management is an area of interest for expobusiness: holding of trade shows serves as a technological basis on which value creation is built. Some part of it becomes the profit of the expobusiness, which, contributing to the economy progress, must itself be improved and developed. For that purpose accumulated business experience by the must be studied, analyzed and generalized. Then, as a product enriched with research results using the latest theories, this experience is redi- rected to expobusiness to serve as scientific support for its activities.

Trade shows are initiated by exhibition companies (organizers). Trade show participants are exhibitors (product suppliers) and visitors (consumers). After a trade show announcement, its organizer begins to form groups of suppliers and consumers and prepares the exhibition platform. Then the organizer brings together both groups on this platform for business communication and making purchase \& sale transactions. As a result, exhibitors and visitors form a two-sided network micro-market at the trade show where value is created in the process of market interactions. The exhibition company helps to maximize this value, hoping that this will allow it to make a larger profit.

The purposes of this research are the following:

- to show how on a discrete sequence of thematically identical short-term trade shows a two-sided network market, which has the identification characteristics of Rochet and Tirole markets can be formed;

- to show how the toolkit of two-sided markets theory can be used to develop the concept of value creation management in the network of exhibition market by influencing its filling with exhibitors and target visitors. 
The main goals of the research were set as follows:

- to develop and classify the exhibition company's business model;

- to algorithmize forming of exhibition two-sided network market, taking into account how value is created in its network;

- to perform identification analysis of features of Roche and Tirole markets and exhibition two-sided network market created and maintained by exhibition company as a multi-party platform;

- to systematize features of the impact of network effects on filling of market sides, taking into account the role of price strategy as a tool for managing value creation in market network by activating the twosided positive cross-network effect;

- to consider system and process features of exhibition business using logistics approach.

\section{Literature review}

For the first time, the term "two-sided markets" was used by D. Gale and L. Shapley, who initiated the eponymous theory (Gale \& Shapley, 1962). It refers to markets where there is no trade as such, where agents of the parties do not use the price equivalent as a criterion for expediency in exchanges. To solve practically important problems, the theory has developed algorithms that allow to create two-way combinations of one / one, one / many, and many / many connections for agents on the market sides without facilitators and money. The contribution to this by L. Shapley and E. Roth (Zhelezova et al., 2013; Roth, 1982, 2003; Shapley \& Scarf, 1974) was awarded Nobel Prize in 2012.

In 2003 J. Rochet and J. Tirole described previously unnoticed type of network markets, which they also called two-sided (Rochet \& Tirole, 2003) The parties in these markets, as in those mentioned above, are two different groups of economic agents. The difference is that the formation and bringing these groups together for making economic exchanges using money is performed by a facilitator firm or a multi-sided platform (Hagiu \& Wright, 2015). The two-sided positive crossnetwork effect is a tool that helps to attract and to place agents on market sides. The asymmetric structure of platform's service price should be used to activate this effect (Rochet \& Tirole, 2006).

These are the main points of the theory of platform two-sided markets of Rochet and Tirole.
The theory gave rise to research aimed at expanding the scope of its application, as well as accumulation, systematization and scientific generalization of answers to questions related to the design of a new and transformation of an existing business.

Two-sided markets are becoming more considerable and demanded in the economy. In this regard, it seems appropriate and relevant to use the development of two-sided markets theory in exhibition business to supplement the base of scientific support for its business practice.

But before exploring necessary for identification features, we analyzed the discussion of platform two-sided markets theory which had taken place since the publication of scientific works of its founders.

In a number of papers the topic of discussion was the use by platform firms of the asymmetric price structure of their services for managing the number of agents on market sides, as well as study results of the role and significance of external effects in the consumption of these services (Armstrong, 2006; Evans \& Schmalensee, 2007; Hagiu, 2006; Rysman, 2009; Weyl, 2010). At the same time, a generally accepted definition of a two-sided market, which is important for antitrust regulation of platform firms business has not yet given although attempts to formulate it have been made (Evans \& Schmalensee, 2016; Luchetta, 2013; Roson, 2005).

The opinion of scientists about signs of identification also differ. An example is the result of testing on three two-sided markets sets of features (Evans \& Schmalensee, 2013; Rochet \& Tirol, 2006; Rysman, 2009) of markets of 11 platforms (Auer \& Petit, 2015): only markets of 7 platforms corresponded to the feature of all three sets. Moreover, the most stringent requirements for features were found in Rochet and Tirole (7 markets), while the other 2 sets allow us to consider two-sided for 10 markets.

Most researchers understand a two-sided market as a market where an intermediary firm sells products or services of two different types to two different groups of agents, and where an increase in sales to one group stimulates the demand of the other group, and Vice versa. An intermediary firm in a two-sided market serves as a platform for direct interaction between these groups of agents (Wright \& Yun, 2019; Sanchez-Cartas \& Leon, 2017; McIntyre \& Srinivasan, 2017).

The two-sided positive cross-network effect is a key defining feature of the two-sided market in the interpretation of Rochet and Tirole. Mitigating 
this feature by replacing it, for example, with a one-sided network effect does not make sense in case of a two-sided exhibition market. Therefore, to identify the latter, the strictest version of features was adopted - the one that was given to twosided markets by the theory founders.

Several analytical reviews are devoted to the theory and aspects of platform two-sided markets operation (Zhao et al., 2019; Sanchez-Cartas \& Gonzalo, 2018; Balandina \& Baskakova, 2016; Kovalenko, 2016; Shastitko \& Parshina, 2016; Yablonskiy, 2013), where:

- it is noted that two-sided markets parties agents get high value along with a reduction in transaction costs;

- a set of conceptual issues is being discussed including the question of characteristics that could become the identification for platform-based two-sided markets.

Many publications consider examples of existing two-sided markets and related platforms, but neither discrete sequences of trade shows, nor relevant two-sided markets, nor exhibition companies, nor expobusiness are discussed.

\section{Research methodology and approach}

Demonstrative example of the exhibition two-sided market helps for better understanding of platform two-sided markets economic nature. This circumstance seems to be a sufficient motive to use theories of platform two-sided markets and formal logic, theories of industry markets and entrepreneurship, theories of design and sociology of markets, general management theory, logistics theory, general systems theory and methods of analysis, decomposition, synthesis, abstraction and generalization to explore exhibition two-sided markets and specifics of managing the organization of short-term trade shows as transactional platforms for exhibitors and target visitors.

The logical framework for developing the concept of value creation management in the twosided exhibition market is built as follows.

Since the business goal of an exhibition company is to make a profit, its main task is to organize a two- sided market, where the parties will be groups of exhibitors and visitors. The network of this market will create value, part of which will be the company's profit. Hence, the production function of the latter is to find a solution. The problem is solved by providing intermediary services to groups of economic agents who need mutually beneficial exchanges. These services have tangible and intangible components. A prepared exhibition transaction platform is a tangible component. The platform parties participate in its production, and the organizing company manages the process (plans, coordinates, analyzes, regulates, etc.). This component is necessary, but not sufficient. In order to manage value creation the organizer must also generate control actions in order to fill the market sides with agents. These impacts are central in the intangible component of services and are produced by the exhibition company itself.

Further development of value creation management concept was based on the axiomatic method and logical deduction. Prerequisites were ordered according to logical reasoning. Three groups of prerequisites were formed for solving the following tasks:

- to define the target function - management quality criterion;

- to identify an economic tool to influence the target function;

- to determine the conditions under which the task of managing value creation can be solved and describe the technology with which these conditions can be met; that is, how to form a two-way network market at the trade show.

To solve the first problem the prerequisites and logical consequence are formulated as follows:

- the value that each of economic agents gets on the two-sided exhibition market, and therefore the total value created on it, is not measurable; while you can manage only what is measured;

- the value created positively depends on the number of mutually beneficial exchanges made in the market, but it cannot be measured;

- the number of exchanges positively depends on the intensity of the flow of business contacts between exhibitors and visitors, but it is impossible to measure it;

- the intensity of contacts flow positively depends on the number of groups of exhibitors and visitors on market sides;

- the number of groups of exhibitors and visitors can be accurately measured even in real time.

Consequence: for the purpose of managing value creation, the target function can be the number of groups of exhibitors and visitors on market sides.

To solve the second problem prerequisites and consequences are as follows: 
- the fullness of market sides depends on the effectiveness of marketing methods and the strength of external network effects of consumption by exhibitors and visitors of the organizer's services;

- increasing the impact on the number of positive network effects can be achieved by using an asymmetric structure of price of the organizer's services, when it subsidizes the access of another group to the second side of the market at the expense of a group of agents on one side of the market.

Consequence: the number of groups of exhibitors and visitors on the sides of exhibition market can be controlled using the asymmetric structure of the organizer's service price.

Thus, the concept of value creation management can be based on the fact that the target function will be the number of groups of exhibitors and visitors, and the management tool will be the structure of price of organizer's services.

A similar approach was used to solve the third problem.

\section{The result No 1 and discussion: exhibition company business model and two-sided exhibi- tion market}

The business model of an exhibition company should provide an opportunity to organize trade show where groups of exhibitors and visitors who form a network market structure can solve their business problems. In addition, it should allow the organizer to make a profit by internalizing part of the value created in the network during market operations.

\subsection{Business processes}

The core of the business model is the main business process (Figure 1). The sequence of its stages covers all stages of the exhibition cycle, when economic resources are converted into services for exhibitors and visitors.

Stages 1-15 form the production phase of the tangible component of services - the material basis for the production and provision of the intangible component:

- notification of manufacturers about the venue and dates of the trade show and requirements for participation (1);

- receipt of applications for participation from potential exhibitors (2);

- processing of applications; approval of documentation and signing of contracts (3);
- payments from exhibitors (4);

- development of booths and expositions preliminary designs (5);

- selection of contractors and suppliers; coordination of tasks and work schedules; signing of agreements with contractors, renters and outsourcers (6);

- development of projects for construction and decoration of the entire exhibition space, including booths (7);

- inviting targeted visitors; advertising (8);

- purchase (rent) of funds for the trade show (equipment, means of advertising, etc.) (9);

- construction of booths and exhibition space, delivery and acceptance of works (10);

- development of a business event program (11);

- release of catalog and information materials (12);

- arrival of exhibitors; delivery of exhibits (13);

- elimination of deficiencies; training of temporary staff (14);

- placement of exhibits on stands (15).

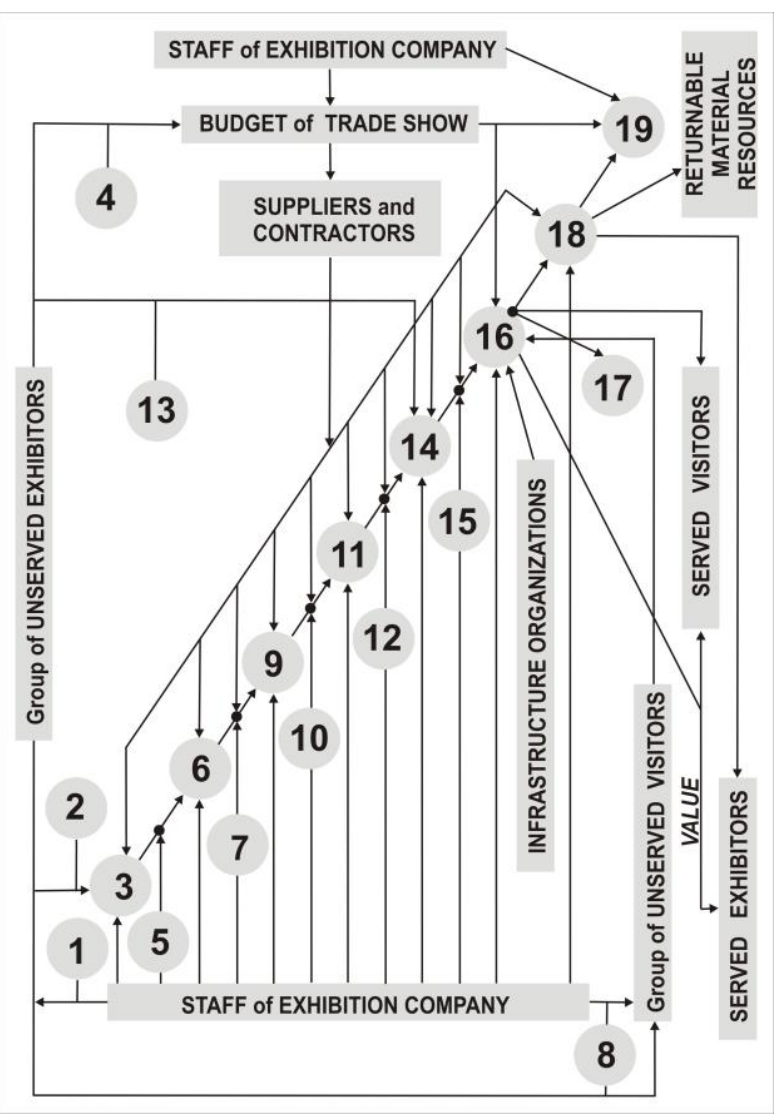

Figure 1. The main business process of economic resources transformation into exhibition services (source: developed by the author) 
Stages 16 (holding of the trade show; servicing a two-sided market) and 17 (the trade show has ended; visitors are leaving) are the stage of an exhibition session when the interaction between exhibitors and visitors (parties) leads to transactions and value creation. The organizer focuses on facilitating the establishment of business contacts between sides.

Stages 18 (departure of exhibitors; removal of exhibits, equipment and dismantled structures returnable material resources) and 19 (summing up, forming feedback signals).

The process model significantly complements the business model basis (Figure 2). It is built taking into account functional logistics cycles and represents processes managed by the exhibition company in accordance with the concept of logistics integration, as well as - trajectories of resource flows and relationships of enterprises involved in processes.

\subsection{Exhibition multi-sided platform}

A set of business processes and supply chains supplemented by a logistics management structure (Figure 1 and 2) gives the concept of exhibition company's business model. It allows the latter to form an exposition, arrange a display platform and solve the problem of attracting numerous groups of exhibitors and visitors. This business model, which provides users with intermediary services that allow them meet on a shared platform and enter into purchase-sale transactions, is classified as a "multisided platform" business model.

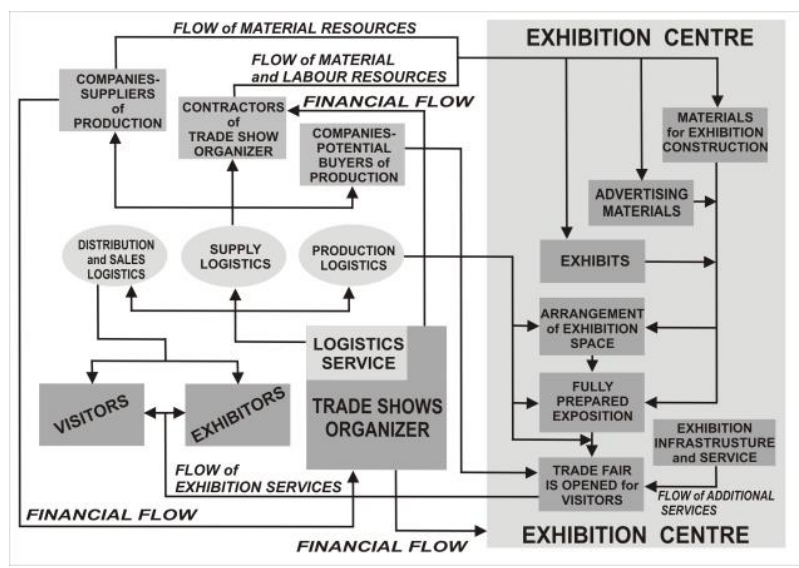

Figure 2. Process model and concept of exhibition services creation and consumption through logistics management (source: developed by the author)

A transaction field as well as a company that uses a multi-sided platform model, is usually also called multi-party platforms. Many exhibitors and visitors, renters, outsourcers, contractors and suppliers are parties to the platform.

At the trade show exhibitors and visitors communicate and make deals. In addition, in the course of getting acquainted with the exhibition and negotiating they get additional value, which is nowhere else especially in the short time that is allotted for the exhibition session it is impossible to get. It consists of commercial and technical information, as well as the opportunity to meet and establish contacts with delegates from industrial and commercial enterprises, business circles and expert community, government agencies and public organizations. At the trade show organizer's clients are provided with advantages that encourage them to become users of the multi-sided platform.

The trade show as a whole is a transactional area, in preparation of which all parties of the multi-sided platform participate. Moreover, the exhibition company, as a service provider, organizer and sponsor of the trade show is associated with it economically, organizationally and legally.

\subsection{Exhibition two-sided market}

Exhibitors and visitors participate in trade show sessions. They study product samples, establish business contacts, sign protocols and other documents based on the results of negotiations and enter into a commercial transactions. More exhibitors and visitors are involved and than branched and larger is market network, more balanced are supply and demand and higher the probability of the most profitable transactions finding and hence the more valuable this market and accordingly services of an organizer for users. Representatives of exhibitors and visitors groups formed on the basis of common thematic interests can establish and develop market relations and make transactions at all consecutive sessions of the same subject. In between agent interactions continue in the development of commercial negotiations that started at the end of the session; transactions are made, and delivery contracts are concluded.

As a result, a quasi-continuous two-sided network market is formed from two- sided micromarkets that operate on a discrete sequence of thematically identical trade show sessions. This market owes its origin to the organizer and its platform business model. To classify this market, it was necessary to examine it for compliance with defining characteristics of platform two-sided markets. 


\section{The result No 2 and discussion: identification of two-sided exhibition market}

The identification procedure was based on the hypothesis that the exhibition two-sided network market can be classified as Rochet and Tirole market.

When identifying platform-based two-sided markets, it seems sufficient to confine ourselves to characteristics that founders of such markets theory gave.

\subsection{Brief statement of features}

In short they can be formulated as follows:

- the market sides should be various multiple groups of agents interacting directly;

- the emergence and existence of a twosided market is possible only through the mediation of a multilateral platform;

- there should be a two-sided positive crossnetwork effect: an increase in the number of agents on one side of the market causes an increase in the number of agents on the other side of the market, and Vice versa.

\subsection{Sides of exhibition market}

The first sign refers to the set of agents on the market sides.

At the exhibition market there are two of them - a group of exhibitors and a group of visitors.

Exhibitors at the trade show demonstrate samples of their product and try to sell it. Each of them receives from the organizer a sublease area at the exhibition and a booth for placing exhibits and staff jobs during the trade show session.

Exhibitors under contracts with the exhibition company invest in trade show funding, information, material and human resources, i.e. on one hand they are investors, suppliers and partners in the process of exhibition services production and at the same time - consumers on the other.

Visitors are invited to the trade show to view the exposition and exhibits, to contact to exhibitors, as well as to obtain various information, market research and consultations. Target visitors participate in production and consumption of services. They have a decisive influence on the success of exhibition event, since the size and quality of the group of exhibitors and the results of the exhibition session depends on their activity.

The exhibition company does not enter into contracts with visitors. They voluntarily come to the trade show that is ready to serve them, communicate directly with exhibitors and buy prod- ucts. The market is created only with the arrival of visitors.

Groups of exhibitors and visitors form two sides of the exhibition network market (Figure 3). Using their interest in cooperation the intermediary company brings them together on it. But their goals and roles are different: exhibitors are suppliers, visitors are consumers. Accordingly, they need different content and volume of service packages.

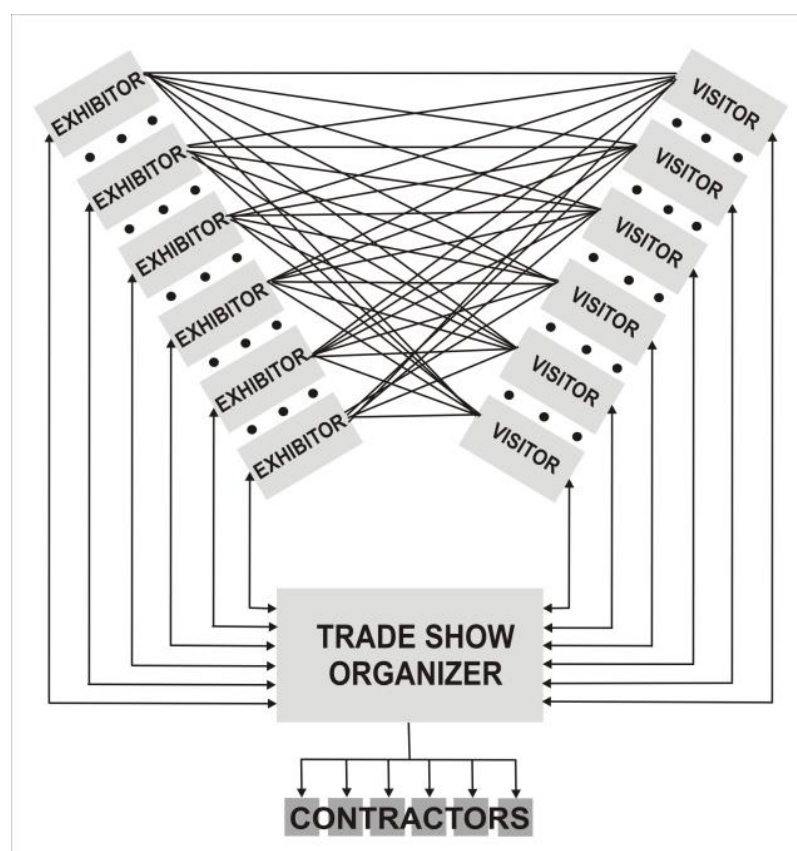

Figure 3. Exhibition two-sided network market (source: developed by the author)

Thus, the exhibition two-sided market has the first defining feature of a platform two-sided market.

\subsection{The role of exhibition company}

As shown above, an exhibition company is a multisided platform. From time to time, it attracts groups of exhibitors and visitors to participate in short-term trade show sessions and forms the sides of the network market where they perform market operations.

Each agent operating in the exhibition market obtains focused on their needs individual services from the platform during the preparation and holding of the trade show, as well as during the postexhibition period. In accordance with this approach for every session a transactional platform is prepared, which provides conditions for the proper positioning of sides - exhibitors as suppliers of products, visitors as consumers, as well as for the functioning of the two-sided market in a sequence of thematically identical trade show sessions. 
Since an exhibition two-sided market is created and served by a multi-party platform throughout the life of the trade show and ceases to exist with it, such a two-sided market has a second defining characteristic.

\subsection{Positive cross-network effect}

An essential feature of the trade show is the following: the more numerous the group of exhibitors and the more interesting enterprises with wellestablished products in the market are involved in it, the more attractive the exhibition event, twosided market on it, and intermediary services of the platform for visitors, and more of them come to the trade show. This is how demand reacts to supply.

The response of exhibitors to the growth in the number and activity of visitors is similar: the more popular is the trade show among visitors, the more benefit exhibitors expect from participating in it. Their demand for platform's services grows, the group of exhibitors replenishes and its quality level increase. This is the response of supply to demand.

Thus, the reaction on side of both visitors and exhibitors to positive quantitative and qualitative changes in cross-groups is positive. This is how two-sided positive cross-network effect is manifested. Using it, the platform can increase the number and quality of users of its services on both sides of the exhibition market, and thus achieve an increase in the number and financial significance of transactions.

Activation of the effect can be provided by the asymmetric structure of price on platform's services: exhibitors pay for everything, subsidizing target visitors who get free access to the exhibition market. This method was found empirically by operators of exhibition services market and was used long before it was theoretically justified.

This effect becomes appreciable when there is already a significant (threshold or critical) number of agents on platform's sides. Therefore, when launching a new platform, when there are no agents on its sides yet and until their number is less than the threshold, it is necessary to resort to more complex procedures to overcome the barrier of entry to the market. Among them, subsidizes by the platform of step-by-step increase in the number of agents on one and the other sides of the platform until two-sided positive cross-network effect gains strength and picks up the process of filling sides. At this point, non-profit period for the sponsor of the platform will end.

It is also useful to note that the price of services includes a profit based on the previously ac- cumulated reputation potential. It implicitly takes into account the expected additional cost that will be created in the exhibition market network due to two-sided positive cross-network effect. Expobusiness has no other way to internalize this additional cost.

So, since the exhibition two-sided market has all three defining features, it should be classified as a platform two-sided market.

\subsection{Network external effects}

Network external effects of consumption, as we know, can be indirect (cross) and direct (onesided). All of them in certain circumstance reveal themselves in exhibition platform two-sided market.

The two-sided positive cross-network effect allows the platform to manage the increase in the number of exhibitors and visitors on both sides of the market. The effect triggered by setting an asymmetric price of services for platform users fades as the trade show and the industry-specific segment covered by it approaches limit parameters. Restrictions are the following:

- size of exhibition area, space for booths and for traffic of visitors;

- duration of exhibition sessions and intervals between them;

- number of potential exhibitors and visitors who taking into account the competitive situation in this segment of the exhibition services market can be added to sides of the exhibition two-sided market.

Positive direct network effects are directed in the same way as positive cross-effects, which contributes to the influx of exhibitors and visitors to market sides. They operate according to the formula "demand stimulates demand".

\section{The result No 3 and discussion: logistics approach and support}

An exhibition company can be considered as a logistics intermediary-service provider, who periodically brings together groups of exhibitors and visitors to engage in market interactions. This creates a value that the company tries to internalize. In order to achieve its business goal intermediary must meet rules that can be formulated similar to "7 rights" logistics rules as follows:

- each exhibition session must be held in a pre-designated location and strictly within the announced time frame;

- numerous groups of exhibitors and visitors should be invited to the session; 
- each exhibitor and visitor in addition to public services must be provided with an individual package of services necessary to participate in two-sided exhibition market;

- services should be provided both at the sessions and in the intervals between them;

- the price of services must be acceptable for both the organizer and the visitors.

\subsection{Logistics system}

An exhibition company, as a sponsor and provider of a multi-sided platform that creates and serves a two-sided exhibition market, must manage its own resources and those provided by sides. The logistics approach involves managing the flow transformation of resources in a coordinated way for existing enterprises. In this case, these companies are parties to the platform and coordinator is the exhibition company. From these enterprises as links the organizer as a focus company should form a platform logistics system. It organizes production connections, resource flow trajectories and business processes that ensure the delivery of components to the exhibition venue and its additional equipment. Such a logistics system can serve as an organizational and technological basis for managing the project of creating a two-sided network market in a discrete sequence of exhibition sessions.

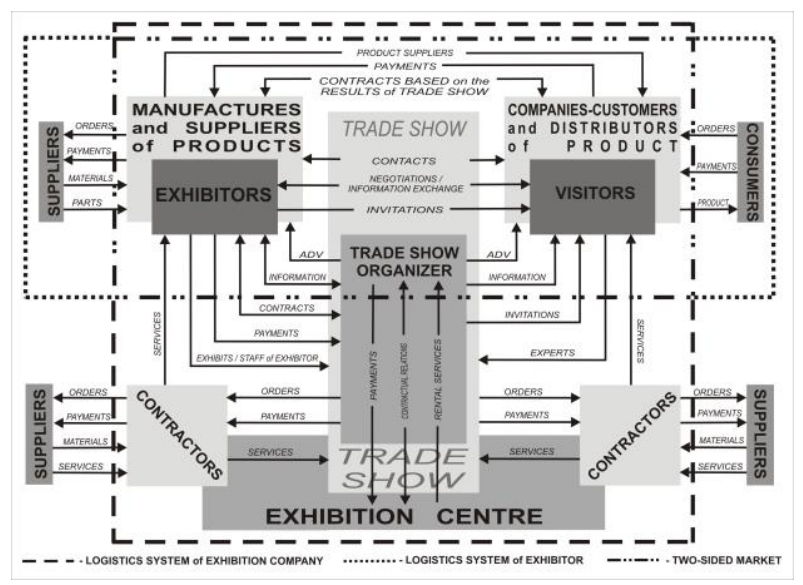

Figure 4. Logistics network of business interactions on multi-sided platform of trade show (source: developed by the author)

All companies in the Exhibitor group also form logistics systems. In each of them in addition to the focal exhibitor company and its suppliers there is one of contractors (visitors) and its endusers, as well as the exhibition company. The latter enters these multiple systems as a link remaining the focal company in the platform logistics system, which intersects with systems where exhibitors dominate. At these intersections there is an exhibition network market where exhibitors and visitors operate; they are served by trade show organizer (Figure 4).

Having formalized their intention to participate in the trade show, exhibitors delegate some of their focal powers to the organizer, while retaining the ability to influence on its management decisions. Being under the influence of numerous exhibitors the exhibition company however must independently manage the flow of resources, coordinate and regulate the activity of all parties of the platform including exhibitors. At the same time, exhibition company is fully responsible for preparation and holding of trade show. Users will evaluate its quality based on the results obtained in two-sided exhibition market.

\subsection{Distribution}

The market for intermediary services of exhibition companies is the buyer's market. Potential users of exhibition company's services are exhibitors and visitors.

At the preparatory stage of each trade show, the organizer enters into contracts with potential exhibitors to form a side of suppliers on two-sided market. The primary attraction of exhibitors is facilitated by an advertising campaign, a flexible price offer, a sensitive attitude of the organizer's staff, as well as consulting and training on the effective participation in the trade show.

It is easier to attract re-participating exhibitors to the suppliers' side. Their commitment to the trade show is supported by special programs that retain, first of all, the most significant contingent of target visitors by encouraging their loyalty (price discounts, priority right to choose a location in the exhibition zone, etc.).

A trade show completes with visitors at the expense of financial resources of exhibitors. So target visitors usually have free access to the exhibition. If this is sufficient for a two-sided positive cross-network effect, it in conjunction with other external effects will bring the market into an equilibrium mode corresponding to the volume of services sold determined by the size of exhibition venue and duration of the event session.

When, despite the measures taken by the exhibition company, the number of visitors remains insufficient, it has to resort to such exceptional means of attracting visitors, such as partial or even full payment of travel and accommodation expens- 
es for the most valuable visitors during the exhibition sessions.

\subsection{Regulation}

The discreteness of two-sided exhibition market affects the management of production and service delivery. First of all, this concerns operational regulation. Its possibilities are limited, since the success or failure of a trade show can only be judged after it is ended and at least preliminary results are summed up, i.e. when it is no longer possible to influence its indicators (Figure 5). The adequacy of corrective measures and regulatory actions can only be assessed after the next session of the event.

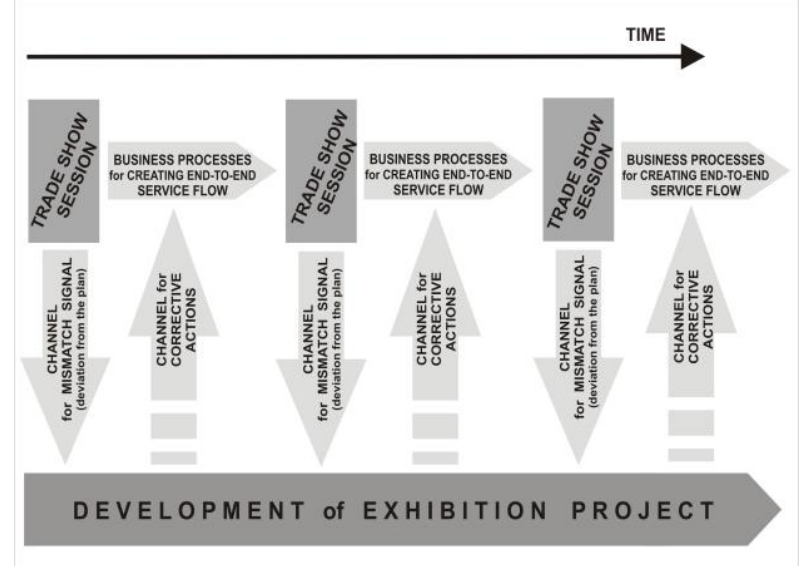

Figure 5. Management of business processes on discrete sequence of trade show sessions (source: developed by the author)

The organizer does not interfere with the essence of operations between exhibitors and visitors. Therefore, it does not have information about the number of interactions and their financial significance. Such information cannot be obtained either through questionnaires or surveys. Moreover, in intervals between exhibition sessions, previously initiated interactions continue and lead to transactions outside the sessions. So as the indicators, the data on the number of exhibitors and visitors can be used only.

In the sequence of exhibition sessions, there is another manifestation of aftereffect. It concerns user loyalty, which can serve as an indicator of the previous exhibition session quality. A high level of loyalty in this session indicates a high level of quality in the previous session, and vice versa: a drop in the level of loyalty indicates that the quality of the previous session is not high enough.

\subsection{Management}

An exhibition company, as a provider of a multisided platform, usually manages the creation and maintenance of a number of two-sided exhibition markets at once (Figure 6).

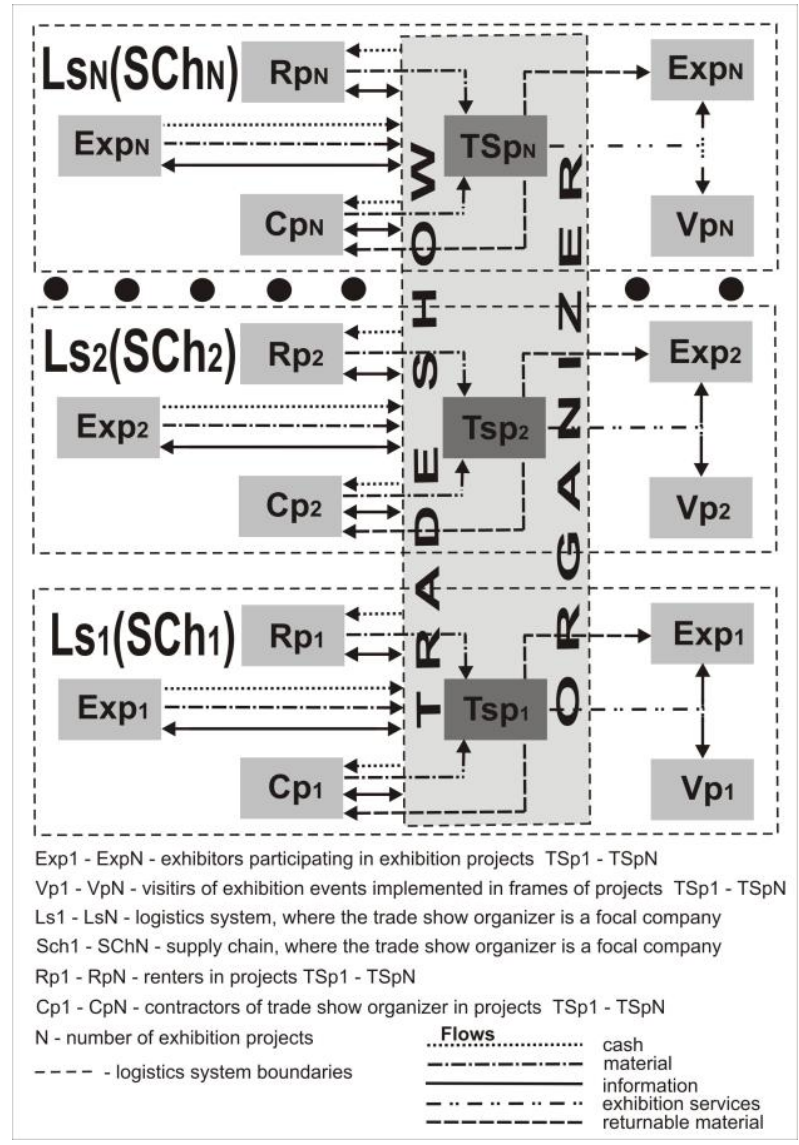

Figure 6. The area of trade show organizer logistics activities (source: developed by the author)

At the same time, its management extends to:

- supply chain enterprises in several platform logistics systems where the exhibition company is the focal point; the number of such systems equals to the number of simultaneously promoted exhibition projects at various stages of readiness;

- exhibitor companies that focus on their logistics systems; the number of communication channels with them depends on the number of exhibitor groups and the number of projects being implemented in parallel;

- companies that send visitors to trade shows; the number of channels for communication with them depends on their number and the number of projects that are simultaneously in operation.

Groups of exhibitors and visitors on sides of exhibition platforms can number many hundreds or even thousands of agents. The organizer's production capacity, structure, and management methods must match the scope and complexity of the tasks. 


\section{Discussions}

The totality of the results obtained makes a certain contribution to the basis of the theory of exhibition markets.

1. For the business model of the autonomous exhibition company as a developer of trade shows and the organizer of their implementation in form of series of thematically identical short-term B2B or/and $\mathrm{B} 2 \mathrm{C}$ exhibition sessions the main business process is proposed and also the process model and management concept for creation and providing of intermediary services to exhibitors and visitors groups is offered; this business model classified as a multi-sided platform.

2. Two-sided exhibition market is presented, where value is created in the process of mutually beneficial exchanges between exhibitors and visitors; it is shown how the market arises and exists on a discrete sequence of trade shows thanks to mediation of the organizer and its platform business model.

3. Identified and described in detail cross and direct external network effects in exhibition twosided network market.

4. An identification analysis was carried out that allowed to classify the exhibition quasicontinuous two-sided network market as a platform-based two-sided market.

5. It is proved that the target function for managing the creation of value in exhibition twosided network market can be the number of exhibitors and visitors on the market sides, and the price structure of the organizer's services can serve as a tool for managing influence.

6 . The results of the study show how the logistics approach can be used to detail production connections, resource flow trajectories and production management scheme for intermediary services in a discrete sequence of exhibition sessions.

7. The development of two-side exhibition markets theory can be facilitated by introduction of the following terms in the scientific dictionary on this topic: platform two-side market; exhibition two-side network market; quasi-continuous exhibition two-side market; exhibition-market session.

\section{Conclusions}

The theory of platform two-sided markets helps to find new directions for the development of exhibition entrepreneurship theory and replenish the scientific base of support for expobusiness. A significant contribution could be, for example, the results of a multi-factor analysis of network effects based on "field" research data, as well as the methodology for evaluating and controlling the quality of exhibition mediation services.

\section{References}

Armstrong, M. (2006). Competition in two-sided markets. RAND Journal of Economics, 37(3), 668691.

https://doi.org/10.1111/j.1756-2171.2006.tb00037.x

Auer, D., \& Petit, N. (2015). Two-sided markets and the challenge of turning economic theory into antitrust policy. The Antitrust Bulleti, 60(4), 426-461. https://doi.org/10.1177/0003603X15607155

Balandina, M. S., \& Baskakova, I. V. (2016). Two-sided markets: Definition, Key elements and instruments for assessment. Izvestia. Ural Federal University Journal, 2(64), 12-20.

Evans, D. S., \& Schmalensee, R. (2016). Matchmakers. The new economics of multi-sided platforms. Harvard Business Review Press. https://doi.org/10.2139/ssrn.2793021

Evans, D. S., \& Schmalensee, R. (2007). The industrial organization of markets with two-sided platforms. Competition Policy International, 3(1), 151-179. https://www.law.berkeley.edu/wpcontent/uploads/2015/04/Evans-Schmalensee-TheIndustrial-Organization-of-Markets-with-TwoSided-Platforms-2007.pdf

Evans, D. S., \& Schmalensee, R. (2013). The antitrust analysis of multi-sided platform businesses. In R. Blair \& D. 1 Sokol (Eds.), Oxford handbook on international antitrust economics. Oxford University Press.

https://papers.ssrn.com/sol3/papers.cfm?abstract_i $\mathrm{d}=2185373$

Gale, D., \& Shapley, L. S. (1962). College admissions and the stability of marriage. American Mathematical Monthly, 69(1), 9-15. https://doi.org/10.1080/00029890.1962.11989827

Hagiu, A. (2006). Pricing and commitment by two-sided platforms. RAND Journal of Economics, 37(3), 720-737.

https://doi.org/10.1111/j.1756-2171.2006.tb00039.x

Hagiu, A., \& Wright, J. (2015). Multi-sided platforms (Working Paper 15-037). Harvard Business School.

Kovalenko, A. (2016). Multi-sided platforms research problematic. Journal of Modern Competition, 10(3(57)), 64-90.

Luchetta, G. (2013). Is the Google platform a two-sided market? Mercato Concorrenza Regole, 15(1), 83118. https://doi.org/10.1093/joclec/nht026

McIntyre, D. P., \& Srinivasan, A. (2017). Networks, platforms, and strategy: Emerging views and next steps. Strategic Management Journal, 38(1), 141160. https://doi.org/10.1002/smj.2596 
Rochet, J. C., \& Tirole, J. M. P. (2003). Platform competition in two-sided markets. Journal of European Economic Association, 1(4), 990-1029. https://doi.org/10.1162/154247603322493212

Rochet, J. C., \& Tirole, J. M. P. (2006). Two-sided markets: A progress report. RAND Journal of Economics, 37(3), 645-667.

https://doi.org/10.1111/j.1756-2171.2006.tb00036.x

Roson, R. (2005). Two-sided markets: A tentative survey. Review of Network Economics, 4(2), 142-160. https://doi.org/10.2202/1446-9022.1070

Roth, A. E. (1982). The economics of matching: Stability and incentives. Mathematics of Operations Research, 7(4), 617-628. https://doi.org/10.1287/moor.7.4.617

Roth, A. E. (2003). The economist as engineer: Game theory, experimentation and computation as tools for design economics. Econometrics, 70(4), 13411378. https://doi.org/10.1111/1468-0262.00335

Rysman, M. (2009). The economics of two-sided markets. Journal of Economic Perspectives, American Economic Association, 23(3), 125-143. https://doi.org/10.1257/jep.23.3.125

Sanchez-Cartas, J. M., \& Gonzalo, L. (2018). Multisided platforms and markets: A literature review. Preprint. 26 p.

https://www.researchgate.net/publication/325225786

Sanchez-Cartas, J. M., \& Leon, G. (2017). Shared networks and market power in two-sided markets. Economics Bulletin, 37(3), 2173-2180.

Shapley, L., \& Scarf, H. (1974). On cores and indivisibility. Journal of Mathematical Economics, 1(1), 23-37.

https://doi.org/10.1016/0304-4068(74)90033-0
Shastitko, A., \& Parshina, E. (2016). Two-sided markets: The subject matter specification. Journal of Modern Competition, 10(1(55)), 5-18.

UFI. (2017). World map of exhibition venues. 46 p. https://www.ufi.org/wp-content/uploads/2018/12/ UFI_World_Map_of_Venues_2017_revDec18.pdf

UFI. (2019). Global economic impact of exhibitions. $40 \mathrm{p}$.

https://www.ufi.org/wp-content/uploads/2019/12/

Global_Economic_Impact_of_Exhibitions_ Dec2019.pdf

UFI. (2020). Global exhibition barometer (24 ${ }^{\text {th }}$ ed.). $72 \mathrm{p}$.

https://www.ufi.org/wp-content/uploads/2020/02/ 24th_UFI_Global_Barometer_february_2020.pdf

Weyl, G. (2010). A price theory of multi-sided markets. American Economic Review, 100, 1642-1672. https://doi.org/10.1257/aer.100.4.1642

Wright, J. D., \& Yun, J. M. (2019). Burdens and balancing in multisided markets: The first principles approach of Ohio v. American Express. Review of Industrial Organization, 54, 717-740. https://doi.org/10.1007/s11151-019-09677-7

Yablonskiy, S. (2013). Multi-sided platforms and markets: Basic approaches, concepts and practices. The Russian Management Journal, 11(4), 57-78.

Zhao, Y., Delft, S., Morgan-Thomas, A., \& Buck, T. (2019). The evolution of platform business models: Exploring competitive battles in the world of platforms. Long Range Planning (in Press). https://doi.org/10.1016/j.lrp.2019.101892

Zhelezova, E., Izmalkov, S., Sonin, K., Khovanskaya, I. (2013). Two-sided markets: Theory and applications. Voprosy Ekonomiki, 1, 4-26. https://doi.org/10.32609/0042-8736-2013-1-4-26 